\title{
Pattern of Medication Prescribing and Factors Associated with Meeting of Target Blood Pressure among Persons with Hypertension in Federal Police Referral Hospital, Ethiopia
}

\author{
Tariku Shimels ${ }^{*}$, Silesh Tadesse ${ }^{2}$, Melesse Abebaw³ ${ }^{3}$ Tariku \\ Tesfaye $^{4}$ and Arebu I Bilal ${ }^{5}$ \\ ${ }^{1}$ St. Paul's Hospital Millennium Medical College Research Resource Mobilization and \\ Project Management Directorate, Ethiopia \\ ${ }^{2}$ Yekatit 12 Hospital Medical Colleges, Department of Pharmacology, Ethiopia \\ ${ }^{3}$ Federal Police Referral Hospital Drug Information Service, Addis Ababa, Ethiopia \\ ${ }^{4}$ Police Health Professionals Training Institute, Ethiopian Police University College, Ethiopia \\ ${ }^{5}$ Addis Ababa University, College of Health Sciences, School of Pharmacy, Department of Pharmaceutics and Social \\ Pharmacy, Ethiopia
}

*Corresponding author: Tariku Shimels, St. Paul's Hospital Millennium Medical College Research Resource Mobilization and Project Management Directorate, Addis Ababa, Ethiopia, Tel: 251-912471223; Email: tarphar2008@gmail.com

\section{Abstract}

Introduction: Hypertension is one of the highly growing chronic health challenges worldwide causing a significant number of deaths and cardiovascular complications. The prevalence of the condition in Ethiopia was estimated to be $19.5 \%$ with an urban and rural subgroup proportion of $25.7 \%$ and $14.7 \%$ respectively. This study was conducted to assess the pattern of prescribing antihypertensive medications and factors associated with BP target meeting among persons with hypertension in Federal Police Referral Hospital.

Method: An institution based cross sectional study was conducted from 15th October 2016 to 15th January 2017. A systematic random sampling technique was employed in selecting the study participants. Data was collected using a semi-structured interview of study participants and visiting medication records. SPSS version 20 was used for data entry and analysis.

Results: Of the 330 subjects required to be included in the study, $318(96.4 \%)$ fulfilled the inclusion criteria and were considered for further analysis. Diuretics were the top prescribed class of antihypertensive agents accounted by 201(63.2\%) of the subjects. Hydrochlorothiazide, a thiazide diuretic, was the most frequent. Next highly utilized classes of drugs included; calcium channel blockers among 172 (54.1\%) subjects followed by angiotensin converting enzyme 
inhibitors prescribed for 153 (48.1\%) participants. Target meeting for the systolic and diastolic blood pressure accounted for $142(44.7 \%)$ and $140(44 \%)$ of the study subjects respectively. Overall target meeting of the two variables was attained by $103(32.4 \%)$ of the participants.

Conclusion: Diuretics were the class of drugs most frequently prescribed succeeded by CCBs and ACEIs. The result of this study has also shown that overall BP target meeting among the subjects was suboptimal. Multivariate binary logistic regression has shown that gender, duration of therapy and dietary adherence were associated with BP target meeting.

Keywords: Blood Pressure; Cross Sectional Study; Ethiopia; Federal Police Referral Hospital; Target Meeting

Abbreviations: AOR: Adjusted Odds Ratio; BP: Blood Pressure; COR: Crude Odds Ratio; DM: Diabetes Mellitus; FPRH: Federal Police Referral Hospital; JNC: Joint National Committee; MRN: Medication Record Numbers; PI: Principal Investigator; SD: Standard Deviation; SPSS: Statistical Package for Social Sciences; SSA: Sub Saharan Africa; STG: Standard Treatment Guideline; TSF: Tea Spoon Full.

\section{Introduction}

Hypertension is one of the highly growing chronic health challenges worldwide accounting for close to 9.4 million deaths every year [1]. A report of population based systematic review from 90 countries in 2016 had indicated that an estimated 1.39 billion people had hypertension in 2010; 349 million in high-income countries and 1.04 billion in low- and middle-income countries [2]. Studies have also mentioned that hypertension in sub- Saharan countries (SSA) is a widespread problem; and at a higher prevalence compared to the developed nations $[3,4]$, its prevalence in some communities been reported to be as high as $38 \%$ [5-7].

The prevalence of hypertension in Ethiopia, according to a systematic meta-analysis in 2015 , was estimated to be $19.5 \%$ with an urban and rural subgroup proportion of $25.7 \%$ and $14.7 \%$ respectively [8]. According to a population based study in Addis Ababa, the capital of the country, the figure went to be even higher to the national prevalence by $10 \%$ for both genders [9].

Hypertension is a major cause of many cardiovascular end organ complications including; myocardial infarction, chronic kidney disease, ischemic hemorrhagic stroke, and heart failure [10-13]. Application of holistic approaches such as dietary measures, drugs, weight reduction and life style modification would be helpful to meet blood pressure targets [14-16].

According to the Seventh Report of the Joint National Committee on Prevention, Detection, Evaluation, and Treatment of High Blood Pressure (JNC 7) [17], and the standard treatment guideline (STG) of Ethiopia [18], a BP target of $<140 / 90 \mathrm{~mm} \mathrm{Hg}$ for most patients with hypertension, and $<130 / 80 \mathrm{~mm} \mathrm{Hg}$ for patients with comorbid diabetes or chronic kidney disease is recommended to attaining substantial reductions in morbidity and mortality.

A considerable variation is noted with reports on BP target meeting across different communities. A systematic review of studies in sub Saharan countries has shown that less than $20 \%$ of the people who have been diagnosed of hypertension maintained a recommended BP target [19]. Apart from this, higher figures have also been reported by recent facility based cross sectional studies in Cameroon and Ethiopia [20-22].

Even though few studies [21,22] have assessed the pattern of medication prescribing and level of BP target meeting among out patients with hypertension in public hospitals of the country, there lacks evidence on how these variables would look like in the police population. This study is, therefore, conducted to assess the pattern of prescribing anti-hypertensive medications and factors associated to treatment target meeting among persons with hypertension attending in the chronic care clinic of federal police referral hospital (FPRH), Ethiopia.

\section{Methods}

\section{Study Setting}

This study was conducted in FPRH which is located in Addis Ababa, the capital of Ethiopia. The hospital has a

Tariku Shimels, et al. Pattern of Medication Prescribing and Factors Associated with Meeting of Target Blood Pressure among Persons with Hypertension in Federal Police Referral Hospital, Ethiopia. Ann Adv Biomed Sci 2019, 2(1): 000124. 
total of 310 beds and is engaged in providing various services including; preventive, diagnostic and medical treatment services to in-patients and out-patients.

\section{Study Design}

An institution based cross sectional study was conducted from 15th October 2016 to 15th January 2017 for a period of three months.

\section{Source Population}

The source population of this study was all outpatients who have been attending to the chronic care clinic of FPRH during the study period and the study population was the persons with hypertension that fulfilled the specified inclusion criteria.

\section{Inclusion and Exclusion Criteria}

The inclusion criteria for the study comprised; persons who had uninterrupted follow up to the clinic since of at least one year back, those aged of 18 years or above, patients who could speak and hear Amharic language and gave verbal informed consent to participate in the interview. On the other hand, those patients with incomplete medical records about their last visit measurement (for persons who were either unable to recall or doubted last visit measures), those with no medication or disease history either in the chronic care clinic or chronic care pharmacy data base and those patients who were not able to attend appointments of the chronic care clinic and pharmacy during the study period were excluded from the study.

\section{Sample Size}

The sample size was calculated based on a population proportion formula and the prevalence of hypertension in the city of Addis Ababa [9].

$$
\mathrm{n}=\frac{(\mathrm{Z} \alpha / \mathbf{2})^{2} \mathbf{P}(\mathbf{1}-\mathbf{P})}{\mathrm{E}^{2}}
$$

Where;

$\mathrm{n}=$ desired sample size

$\alpha=0.05$ or $Z \alpha / 2=1.96$ for level of confidence

$\mathrm{P}=0.3$, (from a population based survey conducted in Addis Ababa, Ethiopia) [9].

$\mathrm{E}=0.05$ for margin of error

$$
\mathrm{n}=\frac{(1.96)^{2} 0.3(1-0.3)}{(0.05)^{2}}=323
$$

After having made an adjustment to the above figure using a reduction formula for the total population of hypertensive outpatients who were on follow up to the chronic care clinic, and adding $10 \%$ non-response rate or incomplete records, we have finally came up with a sample size of 330 participants.

\section{Sampling Technique}

A systematic random sampling technique was employed in selecting the study participants. Initially, the total number of study subjects was identified based on their chronic care clinic visit and medication refill appointment dates in the chronic care pharmacy unit database. As refills were done every three months, the sampling interval was determined by dividing the total number of persons with type 2 diabetes mellitus (DM) to the required sample size. Accordingly, a random integer between 0 and the sampling interval was selected, and selection was continued till the end based on the subject's appointment date to refill the medications.

\section{Data Collection Procedure and Quality}

Data was collected using a semi-structured interview of study participants by a trained pharmacist. Interview was scheduled based on the participants' refill date to the chronic care pharmacy unit. After obtaining their consent, participants were briefed about the purpose of the study, and invited whether they would want to participate in the study. They were also assured to withdraw from the interview at any moment if they are uncomfortable. Sociodemographic characteristics, disease history, and adherence issues were recorded by interviewing the participants. Last visit outcome results were taken from medication charts based on the medication record numbers (MRNs). Classes of drugs prescribed, type of therapy and number of drugs were identified from prescription papers and database records.

For ensuring consistency and data quality, interview was conducted in Amharic (a national working language which all participants speak). The data collector was trained for two days on the relevance of the study, data collection techniques, informed consent and confidentiality of the data collected. Prior to the start of the data collection period, a pilot of 30 subjects' medication records, obtained from the chronic care clinic, was evaluated against the required variables in the study. Completeness of data collected was checked every day by the principal investigators (PIs).

\section{Operational Definitions}

Blood pressure target meeting: was measured based on either the systolic or diastolic pressure reports of the 
participant. Consequently, in subjects aged 60 or above, BP target was considered met if systolic measure was $<150 \mathrm{mmHg}$ and diastolic measure $<90 \mathrm{mmHg}$. In the subjects below the age of 60 , BP target was considered met if systolic measure was $<140$ and diastolic measure was $<90 \mathrm{mmHg}$ irrespective of chronic kidney disease or diabetes mellitus presence.

Dietary adherence: Was measured based on vegetable, fiber, salt, fat and alcohol intake levels. It was considered good if the participant reports to take at least 2 servings of vegetables/fruits for $\geq 3$ days/week, whole grains, fiber or fish at least 2 servings for $\geq 3$ days/week, small amount of fat or sugar, less than 2.3g salt $(<1 \mathrm{TSF})$ intake per day, and less than $600 \mathrm{ml}$ alcoholic intake per day.

Exercise adherence: Was considered active if participant reported to exercise for at least 30 minutes in $>=4$ days of the week.

Medication adherence: Was measured based on a participant's reported daily missed doses of the prescribed anti-diabetic medications. If participant has not missed more than 80 percent of the doses in a month, it was assumed good adherence.

\section{Ethics Approval and Consent}

The study was approved by the School of Pharmacy Research and Ethics committee, College of Health Sciences, Addis Ababa University. Before the start of actual data collection, permission was obtained from Federal Police Health Service Directorate. The study was conducted with an informed consent acquired from each participant, and the data collection was conducted confidentially. Personal identifiers such as; MRN, Name, Address, or telephone number were not included in the personal information interview.

\section{Data Analysis}

After coded and checked manually for completeness, data was entered into statistical package for social sciences (SPSS) version 20 and cleaned before analysis. Frequency distributions and percentage tables were used to present socio-demographic variables and participants' characteristics. A binary logistics regression was carried out for determining factors associated with target meeting of the outcome measure. Target meeting of each outcome variable was tested individually and in combination. Because a national hypertension management guideline is not available in Ethiopia, target levels used in this study were set based on the recommendations in the Eighth Joint National Committee (JNC8) and Ethiopian standard treatment guidelines $[17,18]$.

\section{Results}

\section{Characteristics of Study Participants}

of the 330 subjects required to be included in the study, 318 (96.4\%) fulfilled the inclusion criteria and were considered for further analysis. The mean age was 56.6 years with median (standard deviation (SD)) of 55.5 (12.4) years ranging from 26 to 89.

Majority of the study participants were in the age group 46 to 60 years $(39.3 \%)$. One hundred eighty nine (59.4\%) were males, and $300(94.3 \%)$ of the participants are married. More than a two third $(72.6 \%)$ of the subjects were military. Close to half (49.1\%) had at least one type of comorbidity. Frequent comorbid conditions included; dyslipidemia in $87(27.4 \%)$, diabetes mellitus in $69(21.7 \%)$, congestive heart failure in $25(7.9 \%)$, arthritis in $10(3.1 \%)$ and, dyspepsia in 6 (1.95) subjects. One hundred seventy two $(54.1 \%)$ of the subjects were taking two individual or combined drug formulations during the study period (Table 1).

\begin{tabular}{|c|c|c|}
\hline Characteristics & Category & N (\%) \\
\hline \multirow{3}{*}{ Age } & $\leq 45$ Years & $93(29.3)$ \\
\cline { 2 - 3 } & $46-60$ Years & $125(39.3)$ \\
\cline { 2 - 3 } Gender & $>60$ Years & $100(31.4)$ \\
\cline { 2 - 3 } & Female & $129(40.6)$ \\
\hline \multirow{2}{*}{ Marital status } & Male & $189(59.4)$ \\
\cline { 2 - 3 } & Mnarried & $300(94.3)$ \\
\hline \multirow{2}{*}{ Military status } & Military & $18(5.7)$ \\
\cline { 2 - 3 } & Nonmilitary & $231(72.6)$ \\
\hline \multirow{2}{*}{ Comorbidity } & No & $162(27.4)$ \\
\cline { 2 - 3 } & Yes & $156(49.9)$ \\
\hline \multirow{3}{*}{ Type of therapy } & 1 drug or mono therapy & $74(23.3)$ \\
\cline { 2 - 3 } & 2 drugs/combination & $172(54.1)$ \\
\cline { 2 - 3 } & 3 drugs or more & $72(22.6)$ \\
\hline
\end{tabular}

Table 1: Characteristics of study participants with hypertension attending the chronic care clinic of Federal Police Referral Hospital, Addis Ababa, 2017 ( $\mathrm{n}=318)$.

\section{Pattern of Prescribing Antihypertensive Drugs to the Study Participants}

Diuretics were the top prescribed class of antihypertensive agents accounted by 201(63.2\%) of the subjects. Hydrochlorothiazide, a thiazide diuretic, was the most frequent. Next highly utilized classes of drugs included; calcium channel blockers among 172 (54.1\%) subjects followed by angiotensin converting enzyme inhibitors prescribed for 153 (48.1\%) participants. Drugs 
that act on both Alpha and beta receptors were the least prescribed (0.6\%) (Table2).

\begin{tabular}{|c|c|}
\hline Drug classes & $\mathbf{N}(\mathbf{\%})$ \\
\hline Diuretics & $201(63.2)$ \\
\hline CCBs & $172(54.1)$ \\
\hline ACEIs & $153(48.1)$ \\
\hline BBs & $97(30.5)$ \\
\hline ARBs & $18(5.7)$ \\
\hline Alpha/Beta blockers & $2(0.6)$ \\
\hline Drug combinations & Frequency (\%) \\
\hline CC+DD & $74(23.3)$ \\
\hline ACEIs+DD & $38(12.0)$ \\
\hline ACEIs+BB+DD & $20(6.3)$ \\
\hline ACEIs+BB+CC & $17(5.4)$ \\
\hline ACEIs+CC & $17(5.4)$ \\
\hline ACEIs+CC+DD & $16(5.0)$ \\
\hline ACEIs+BB & $15(4.7)$ \\
\hline BB+CC & $13(4.1)$ \\
\hline BB+DD & $10(3.2)$ \\
\hline ACEIs+BB+CC+DD & $5(1.6)$ \\
\hline
\end{tabular}

Table 2: Class of drugs prescribed for persons with hypertension in Federal Police Referral Hospital, Addis Ababa, 2017 $(\mathrm{n}=318)$.

Key: CCBs: calcium channel blockers, ACEIs: Angiotensin converting enzyme inhibitors, BBs: beta blockers, ARBs: angiotensin receptor blockers, Alpha/beta: both alpha and beta receptor blockers, DDs: diuretics.

Common Antihypertensive Drugs taken by Patients

Table 3 below shows the top ten antihypertensive drugs prescribed to the patients during the study period.
Accordingly; hydrochlorothiazide, a thiazide diuretic agent, was the most frequently prescribed drug among $169(53.1 \%)$ subjects followed by Enalapril by 140 $(44.0 \%)$ and nefidipine by $121(38.1 \%)$ subjects.

\begin{tabular}{|c|c|c|}
\hline Drug & Frequency & Percent \\
\hline Hydrochlorothiazide & 169 & 53.1 \\
\hline Enalapril & 140 & 44 \\
\hline Nefidipine & 121 & 38.1 \\
\hline Atenolol & 52 & 16.4 \\
\hline Metoprolol & 34 & 10.7 \\
\hline Felodipine & 33 & 10.4 \\
\hline Furosemide & 18 & 5.7 \\
\hline Amlodipine & 18 & 5.7 \\
\hline Spironolactone & 14 & 4.4 \\
\hline Lisinopril & 13 & 4.1 \\
\hline
\end{tabular}

Table 3: Common antihypertensive drugs prescribed for persons with hypertension in Federal Police Referral Hospital, Addis Ababa, 2017 ( $\mathrm{n}=318)$.

\section{Factors Associated with Blood Pressure Target Meeting}

The median of last visit systolic blood pressure in the present study was $140 \mathrm{mmHg}$ with mean (SD) of 138.7(17.25) and range of 100 to $180 \mathrm{mmHg}$. Similarly, median of diastolic blood pressure was $90 \mathrm{mmHg}$ with mean (SD) of 87.6 (9.6) and range of 60 to $120 \mathrm{mmHg}$. Target meeting for the systolic and diastolic blood pressure accounted for $142(44.7 \%)$ and $140(44 \%)$ of the study subjects respectively. Overall target meeting of the 
two variables was attained by $103(32.4 \%)$ of the participants. As presented in the table below, blood pressure was considered in terms of the combined outcome of the systolic and diastolic measures for determining possible factors associated with treatment target meeting.

Male gender was associated with a close to half chance of treatment target meeting as compared to being a female (AOR: 0.51, 95\% CI: 0.28-0.93). This study has also shown that patients who have been on antihypertensive therapy for more than 5 years were less likely to attain treatment target compared to those who took therapy for 5 years or less (AOR: 0.51, 95\% CI: 0.27-0.95). On the other hand, good dietary adherence has shown a positive association with target meeting of antihypertensive therapy (AOR: 5.52, 95\% CI: 2.74-11.11) (Table 4).

\begin{tabular}{|c|c|c|c|c|c|}
\hline \multirow{2}{*}{\multicolumn{2}{|c|}{ Characteristics }} & \multicolumn{2}{|c|}{ Target BP controlled } & \multirow{3}{*}{$\begin{array}{c}\text { COR }(\mathbf{9 5 \%} \% \mathbf{C I}) \\
\text { Ref }\end{array}$} & \multirow{3}{*}{$\begin{array}{c}\text { AOR }(\mathbf{9 5 \% C I )}) \\
\text { Ref }\end{array}$} \\
\hline & & \multirow{2}{*}{$\begin{array}{l}\text { Yes (\%) } \\
31(33.3)\end{array}$} & \multirow{2}{*}{$\begin{array}{c}\text { No (\%) } \\
62(66.6)\end{array}$} & & \\
\hline \multirow{3}{*}{ Age (Years) } & $\leq 45$ & & & & \\
\hline & $46-60$ & $46(36.8)$ & $79(63.2)$ & $1.17(0.66-2.10)$ & $1.80(0.90-3.60)$ \\
\hline & $>60$ & $26(26.0)$ & $74(74.0)$ & $0.70(0.38-1.31)$ & $1.27(0.57-2.83)$ \\
\hline \multirow{2}{*}{ Gender } & Female & $56(43.4)$ & $73(56.6)$ & Ref & Ref \\
\hline & Male & $47(24.9)$ & $142(75.1)$ & $0.43(0.27-0.70)$ & $0.51(0.28-0.93)^{*}$ \\
\hline \multirow{2}{*}{ Military status } & Military & $70(30.0)$ & $161(70)$ & $0.71(0.43-1.20)$ & $1.31(0.68-2.52)$ \\
\hline & Non-military & $33(70.0)$ & $54(62.0)$ & Ref & Ref \\
\hline \multirow{2}{*}{ Comorbidity } & No & $52(32.0)$ & $110(68)$ & Ref & Ref \\
\hline & Yes & $51(32.7)$ & $105(67.3)$ & $1.03(0.64-1.64)$ & $1.14(0.66-1.97)$ \\
\hline \multirow{2}{*}{ Duration of therapy (Yrs.) } & $\leq 5$ & $68(38.0)$ & $111(62)$ & Ref & Ref \\
\hline & $>5$ & $35(25.2)$ & $104(74.8)$ & $0.55(0.34-0.90)$ & $0.51(0.27-0.95)^{*}$ \\
\hline \multirow{3}{*}{ Type of therapy } & 1 drug/ mono therapy & $29(39.2)$ & $45(60.8)$ & Ref & Ref \\
\hline & 2 drugs/ combination & $54(31.4)$ & $118(68.6)$ & $0.71(0.40-1.25)$ & $0.78(0.42-1.47)$ \\
\hline & 3 or more drugs & $20(27.8)$ & $52(72.2)$ & $0.60(0.30-1.20)$ & $0.66(0.29-1.49)$ \\
\hline \multirow{2}{*}{ Dietary adherence } & Poor & $13(12.1)$ & $94(87.9)$ & Ref & Ref \\
\hline & Good & $90(42.7)$ & $121(57.3)$ & $5.40(2.83-10.21)$ & $5.52(2.74-11.11)^{*}$ \\
\hline \multirow{2}{*}{ Physical exercise } & Inactive & $12(25.5)$ & $35(75.5)$ & Ref & Ref \\
\hline & Active & $91(33.6)$ & $180(66.4)$ & $1.46(0.73-3.00)$ & $0.89(0.38-2.11)$ \\
\hline \multirow{2}{*}{ Medication adherence } & Poor & $5(20.0)$ & $20(80.0)$ & Ref & Ref \\
\hline & Good & $98(33.4)$ & $195(66.6)$ & $2.01(0.73-5.52)$ & $1.13(0.38-3.30)$ \\
\hline
\end{tabular}

Table 4: Multivariate association of selected characteristics with BP target meeting among persons with hypertension in Federal Police Referral Hospital, Addis Ababa, 2017 ( $\mathrm{n}=318)$.

*Statistically significant; Ref: reference

\section{Discussion}

In the present study, it was identified that diuretics were the class of drugs most frequently prescribed $(63.2 \%)$ either as a monotherapy or in combination with other antihypertensive agents. Hydrochlorothiazide, a thiazide diuretic, accounted the top rank (84.1\%) from the class. As a class of drugs ever prescribed to study participants, CCBs and ACEIs also come to occupy the next order to diuretics. This pattern of prescribing is in line with the eighth joint national committee (JNC8) and Ethiopian standard treatment guideline (STG) recommendations $[17,18]$.
Nearly two-third of the subjects, in this study, was in the age group below 60 , and a considerable prevalence of diabetes $(21.7 \%)$ was noted as comorbidity. Remarkably, the protocol used in such scenarios for most of the cases, was in agreement to choice of first line regimens mentioned in the guidelines. The most frequent use of hydrochlorothiazide and diuretics' combination with CCBs and ACEIs has also been reported by facility based studies in the literature [23-25]. The fact that ARBs were least utilized next to ACEIs may imply that subjects were in compliance to their start up medications or experienced lesser side effects from the latter class. 
Treatment target meeting after having undergone a monotherapy or combination regiment was another concern in the present assessment. Because hypertension management involves several approaches apart from drugs, the result of this study has shown that overall BP target meeting was suboptimal (32.4\%). Nonetheless, target meeting of only either the systolic $(44.7 \%)$ or diastolic (44\%) BP was relatively higher than the combined measure. Lower figures of BP target meeting were reported as; $7.84 \%$ among outpatients in Angola [26], 31\% in Italy [27] and 24.6\% in Cameroon [28].

In contrast to the present result; higher results have also been documented by studies done in Cameroon [20], Ethiopia [21,22], France, UK, Germany, US and Spain [27]. Whereas, study designs employed were similar, a number of factors could contribute for the observed variation across different nations. These may include; patients' awareness to medication adherence, type and number of medicines used, cut points of BP target considered and type of comorbidity [29], as well as environmental and genetic variations among others.

The multivariate binary logistic regression test has shown that male gender was associated with a close to half chance of treatment target meeting as compared to being a female (AOR: 0.51, 95\% CI: 0.28-0.93). This difference could be ascribed to the higher prevalence of comorbidities that potentially impact treatment outcome prominently; dyslipidemia (57.5\%), heart failure (60\%) and diabetes mellitus (66.7\%) as well as, intake of herbal medicines among the male subjects (60\%). Similar results have documented that male gender was associated to poor BP target meeting [30,31].

The current study also shows that participants who have been on antihypertensive therapy for more than 5 years were less likely to attain treatment target compared to those who took therapy for 5 years or less. The impaired outcome among these subjects would be supplemented by the more frequent comorbid conditions and lower adherence to diet compared to the reference sub-group. On the other hand, good dietary adherence has shown a positive association with target meeting of antihypertensive therapy (AOR: 5.52, 95\% CI: 2.74-11.11).

This study has tried to explore the pattern of antihypertensive medication prescribing and factors potentially associating to target meeting of therapy among a police community in the country. The findings may, thus, serve as a baseline for future studies targeting
BP management. However, the findings must be seen in light with certain limitations such as; a cross sectional design used and, a single point outcome measure of blood pressure.

\section{Conclusion}

Diuretics were the class of drugs most frequently prescribed either as a monotherapy or in combination with other agents in which hydrochlorothiazide accounted the top rank. As a class of drugs ever prescribed to study participants, CCBs and ACEIs have occupied the next order to diuretics. The result of this study has also shown that overall BP target meeting among the subjects was suboptimal. Nonetheless, target meeting of only either the systolic or diastolic BP was relatively higher than the combined measure. The multivariate binary logistic regression test has shown that male gender was associated with a close to half chance of treatment target meeting as compared to being a female. Similarly, increase in treatment duration was found to be associated with poor BP target meeting while good dietary adherence predicted target meeting of $\mathrm{BP}$ treatment.

\section{Ethical Approval and Consent}

The study was approved by the School of Pharmacy Research and Ethics committee, College of Health Sciences, Addis Ababa University. Before the start of actual data collection, permission was obtained from Federal Police Health Service Directorate. The study was conducted with an informed consent acquired from each participant, and the data collection was conducted confidentially. Personal identifiers such as medical record number (MRN), Name, Address, or telephone number were not included in the personal information interview.

\section{Consent for Publication}

Not applicable

\section{Availability of Data}

The datasets during and/or analyzed during the current study are available from the corresponding author.

\section{Competing Interests}

The authors declare that they have no competing interests. 


\section{Funding}

There is no source of funding.

\section{Authors' Contributions}

TS and AI designed the proposal while TT and MA were involved in the supervision of the data collection. TS did the data entry while AI and ST completed the analysis. All of the authors have been involved in the write up and approval of the final manuscript.

\section{Acknowledgements}

We would like to thank the staff members of the chronic care clinic and chronic care pharmacy unit of federal police referral hospital for their unreserved support during the conduct of this study. We, also, forward our heartily gratitude to persons with chronic illnesses and who have given informed consent to participate in this study.

\section{References}

1. Lim SS, Vos T, Flaxman AD, Danaei G, Shibuya K, et al. (2012) A comparative risk assessment of burden of disease and injury attributable to 67 risk factors and risk factor clusters in 21 regions, 1990-2010 : a systematic analysis for the Global Burden of Disease Study 2010. Lancet 380(9859): 2224-2260.

2. Dreisbach AW (2013) Epidemiology of Hypertension. Supplement to JAPI February 61: 12-13.

3. Vijver SVD, Akinyi H, Oti S, Olajide A, Agyemang C, et al. (2013) Status report on hypertension in AfricaConsultative review for the 6th Session of African Union Conferee of Ministers of Health on NCDs. Pan Afr Med J 16: 38.

4. Katherine T, Joshua D, Tanika N, Jennifer E, Patricia M, et al. (2016) Global Disparities of Hypertension Prevalence and Control: A Systematic Analysis of Population-Based Studies From 90 Countries. Circulation 134(6): 441-450.

5. Ataklte F, Erqou S, Kaptoge S, Taye B, EchouffoTcheugui JB, et al. (2015) Burden of undiagnosed hypertension in sub-saharan Africa: a systematic review and meta-analysis. Hypertension 65: 291-298.

6. Opie LH, Seedat YK (2005) Hypertension in subSaharan African populations. Circulation 112(23): 3562-3568.
7. Misganaw A, Mailemrariam D, Araya T (2012) The double mortality burden among adults in Addis Ababa, Ethiopia, 2006-2009. Prev Chronic Dis 9: 110142.

8. Kibret K, Mesfin Y (2015) Prevalence of hypertension in Ethiopia: a systematic meta-analysis. Public Health Reviews 36: 14.

9. Tesfaye F, Byass P, Wall S (2009) Population based prevalence of high blood pressure among adults in Addis Ababa: uncovering a silent epidemic. BMC Cardiovascular Disorders 9: 39.

10. Flack JM, Peters R, Shafi T, Alrefai H, Nasser SA, et al. (2003) Prevention of hypertension and its complications: theoretical basis and guidelines for treatment. J Am Soc Nephrol 14(7): S92-S98.

11. Yuflih FF, Yulia S, Anam OP, Hadyana S, Rully R (2014) Prevalence of Hypertension and Its Complications in Jatinangor. Journal of Hypertension.

12. Savard S, Amar L, Plouin P, Steichen O (2013) Cardiovascular Complications Associated With Primary Aldosteronism: a controlled Cross-Sectional Study. Hypertension 62(2): 331-336.

13. Rosas-Peralta M, Borrayo-Sánchez G, Madrid-Miller A, Ramírez-Arias E, Pérez-Rodríguez G (2016) Cardiovascular complications of hypertensive crisis. Rev Med Inst Mex Seguro Soc 54(S1): S67-S74.

14. McInnes GT (1999) Integrated approaches to management of hypertension: promoting treatment acceptance. Am Heart J 138(3): 252-255.

15. Oparil S, Schmieder RE (2015) New approaches in the treatment of hypertension. Circ Res 116(6): 10741095.

16. World Health Organization (2013) A global brief on hypertension. World Health Day.

17. James PA, Oparil S, Carter BL, Cushman WC, Dennison-Himmelfarb C, et al. (2014) The 2014 Evidence-Based Guideline for the Management of High Blood Pressure in Adults; Report from the Panel Members Appointed to the Eighth Joint National Committee (JNC8). JAMA 311(5): 507-520.

18. Standard Treatment Guideline for General Hospital (2010) Hypertension. $2^{\text {nd }}$ (Edn.), Drug Administration and Control Authority of Ethiopia 2010: 115-117. 
19. Addo J, Smeeth L, Leon DA (2007) Hypertension in sub-Saharan Africa; a systematic review. Hypertension 50(6): 1012-1018.

20. Menanga A, Edie S, Nkoke C, Boombhi J, Musa AJ, et al. (2016) Factors associated with blood pressure control amongst adults with hypertension in Yaounde, Cameroon: a cross-sectional study. Cardiovasc Diagn Ther 6(5): 439-445.

21. Mulatu HA, Bayisa T, Berhe T, Woldeyes E (2017) Pattern of Antihypertensive Treatment and Blood Pressure Control among Diabetic Outpatients in Addis Ababa, Ethiopia. J Diabetes Metab 8: 738.

22. Asgedom SW, Gudina EK, Desse TA (2016) Assessment of Blood Pressure Control among Hypertensive Patients in Southwest Ethiopia. PLoS ONE 11(11): e0166432.

23. Johnson ML, Singh H (2005) Patterns of Antihypertensive Therapy among Patients with Diabetes. J Gen Intern Med 20(9): 842-846.

24. Osibogun A, Okwor TJ (2017) Anti-Hypertensive Prescription and Cost Patterns in an Outpatient Department of a Teaching Hospital in Lagos State Nigeria. Open Journal of Preventive Medicine 4: 156163.

25. Wang J, Staessen JA, Franklin SS, Fagard R, Gueyffier FO (2005) Systolic and Diastolic Blood Pressure Lowering as Determinants of Cardiovascular Outcome. Hypertension 45(5): 907-913.
26. Paquissi FP, Cuvinje ABP, Cuvinje AB, Paquissi AM (2016) Hypertension among Outpatients at a General Hospital in South Angola: Prevalence, Awareness, Treatment, and Control. Clin Med Insights Cardiol 10: 111-116.

27. Wang YR, Alexander GC, Stafford RS (2007) Outpatient Hypertension Treatment, Treatment Intensification, and Control in Western Europe and the United States. Arch Intern Med 167(2): 141-147.

28. Dzudie A, Kengne AP, Muna WF, Ba H, Mananga A, et al. (2012) Prevalence, awareness, treatment and control of hypertension in a self-selected sub-Saharan African urban population: a cross-sectional study. BMJ Open 2(4): e001217.

29. Xu D, Chen W, Li X, Zhang Y, Li X, et al. (2013) Factors associated with blood pressure control in hypertensive patients with coronary heart disease: evidence from the Chinese Cholesterol Education Program. PLoS One 8(5): e63135.

30. Silva SSBE, Oliveira SFSB, Pierin AMG (2016) The control of hypertension in men and women: a comparative analysis. Rev Esc Enferm USP 50(1): 5058.

31. MacDonald K, Lee CS, Chen HC, Ko ML, Fidel GE, et al. (2011) Gender-specific, multi-level determinants of outcomes of antihypertensive treatment: a subanalysis of the Belgian PREVIEW study. J Hum Hypertens 25(6): 372-382. 